\title{
ON THE GENETIC MANIPULATION OF ANIMALS
}

\author{
EVELYN PLUHAR \\ Pennsylvania State University
}

Certain experiments have recently borne some rather amazing fruit. Researchers at the Institute of Animal Physiology in Cambridge, England, have succeeded in creating a "chimera." Through embryonic manipulation, genetic materials from goats and sheep have been combined to produce a very odd beast: the geep. This goat in sheep's clothing is sterile at present, like the mule, but unlike the mule, it has two pairs of exceedingly similar parents.[1] In the U.S., giant mice --first bearing rat genes, then human genes-have been bred. Some of them have passed on their traits to a second generation. The Department of Agriculture is now conducting research in Beltsville, Maryland, which it expects to lead to the breeding of sheep and pigs twice the normal size. (They, too, will bear some human genes.)[2] Super-cattle are next on the list. According to University of Pennsylvania microbiologist Ralph Brinster, "If we can make bigger mice, we can make bigger cows." [3]

These are but a few of the developments which biotechnology is making possible. The splitting of genes and embryonic manipulation have, in the course of little over one "decade, made it possible for humans to alter nature in unprecedented ways. Is such manipulation ever ethically justifiable, or is it an unwarranted human intervention in the course of nature?

In this paper. I will focus on the genetic manipulation of those species closest to us in evolutionary terms: sentient, nonhuman animals. Consideration of this issue will inevitably lead us here to questions about the genetic manipulation of human animals. Many, myself included, are deeply disturbed by the sorts of experiments described above. However, I will argue that the objections which are now being raised against such research are misguided. Sontrary to what many critics say, I believe that genetic manipula-

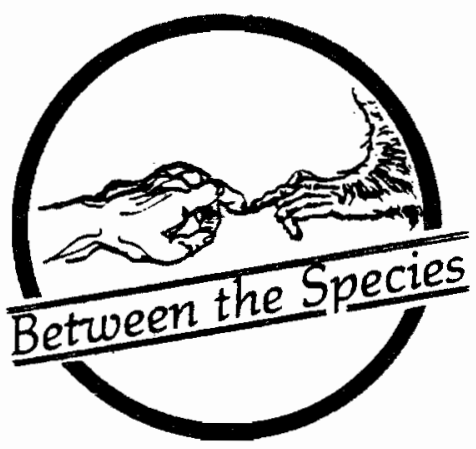

tion in itself is not wrong. On the contrary, although much current research in this area is indeed ethically questionable, genetic manipulation could greatly improve the lives of nonhuman and human animals and ought to proceed.

Many objections are now being raised against the genetic manipulation of sentient nonhuman animals. Let us consider each in turn.

1. Economist Jeremy Rifkin, author of the popular 1983 critique of genetic manipulation Algeny, recently joined forces with the Humane Society of the United States in a suit filed to halt the "super-livestock" experiments in Maryland. The suit contends that, among other things, the experiments are a "new and insidious form of cruelty toward animals by robbing them of their unique genetic makeup."[4]

This objection seems to be off the mark. These experiments will probably result in cruelty, but the cruelty would not consist in "robbing" the sheep and pigs of their "unique genetic makeup." First of all, the "robbery" has long since occurred. Conventional animal breeding has altered these species to such an extent that their wild ancestors would no longer recognize them. We have fattened and dulled them into meat and textile machines.[5] Cattle and chickens have had similar fates. "Genetic farming" is simply an extension of the traditional human manipulation of nonhuman animal species for our own convenience. But the main point to be made

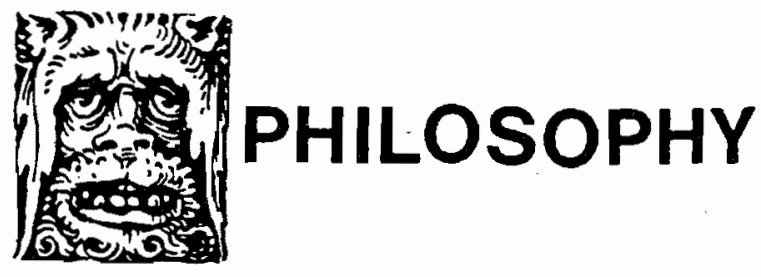


here is that genetic manipulation is not in itself cruel, nor need it lead to cruelty. The experiments in question will most likely lead to cruelty because they show an utter lack of respect for sentient nonhuman animals. "Livestock" is a very revealing term. To treat pigs, for example, as pork chops with hooves is to assume that they have no value in their own right, no lives worth living apart from our own appetites. It is this lack of respect which causes the miseries suffered under intensive factory farming. [6] Such cruelty is motivated by something far worse than malice: indifference. No doubt "super-livestock" would be treated with at least as much indifferent cruelty as traditional pigs, sheep, and cattle; perhaps they would even be subject to more confinement, given that their size would call for greater "control." We have good reason to deplore this manner of cruelty, whether it be due to factory farming or to genetic farming.

Genetic manipulation is not the culprit here. on the contrary, genetic manipulation may be motivated by respect and concern for individuals rather than by the opposite. Suppose that we became able to correct severely crippling and painful genetic disorders in humans, as many researchers hope to do. Do we "rob" a potential victim of sickle-cell anemia of his "unique genetic makeup" if we make use of the procedure? Would we be guilty of cruelty? It is not difficult to inagine what a current victim of this disease would reply to that question. By alleviating his/her suffering and making a normal life possible for him/her, we show maximm respect and concern for that individual. Similarly, if we were to use genetic engineering to eliminate crippling hereditary diseases in nonhuman animals or to make them less susceptible to disease, we could hardly be accused of lack of respect or cruelty.

2. At this point, a second objection can be pressed. A critic of genetic manipulation might concede that individuals could be helped by the new biotechnology and yet remained opposed to such methods on the grounds that species are threatened by them. Alterations which would be passed on to future generations may debase and ultimately destroy a species. Evolutionary biologist Stephen Jay Gould, who in the course of a devastating expose of Algeny's inaccurate and shoddy scholarship declares himself in agreement with Rifkin's conclusions, puts the objection well:

You [Rifkin] have rejected us, reviled us, but we are with you. We are taxonomists, ecologists, and evolutionists-most of us Darwinians. We have devoted our lives to the study of species in their natural habitats. We have struggled to understand--and we greatly admire-the remarkable construction and operation of organisms, the product of complex evolutionary histories, cascades of astounding improbability stretching back for millions of years. We know these organisms, and we love them-as they are. [7]

This objection raises the very difficult and intriguing issue of whether species are morally considerable (i.e., worthy of consideration in their own right). If so, what is their moral significance (i.e., degree of moral considerability) in relation to the individuals who constitute them? settling this extremely difficult matter is beyond the scope of this paper.[8] Nevertheless, I believe that this objection can be handled, even if one assumes that species are morally considerable.

Genetic manipulation can be used to preserve species which would otherwise probably disappear. Human actions in the past have eliminated many species and made it difficult for some remaining ones to survive. Biotechnology could be used to rectify some of this damage. Consider the giant panda. It depends on a special variety of bamboo. Due to a combination of human encraachment on its territory and the cyclical nature of the bamboo, the panda is now severely endangered. could we but re-engineer the bamboo or the panda, the species could be saved. Already. unusual methods to save the species are being used: pandas are captured, and if normal breeding fails to occur (it almost never does in captivity), artificial insemination is used. Why not use biotechnology to supplement these methods? (A by-product of genetic manipulation research also suggests a promising technique. The geep experiments, in which the genetically intermingled embryos of goats and sheep are carried to term by surrogate sheep and goat mothers, have excited many researchers because it suggests that the embryos of endangered species could be car- 
ried more successfully by surrogate mothers of other species.[9] The panda, as well as other endangered species plagued by difficult pregnancies, might benefit greatly from this method, too.)

There is another possible advantage for species for us to consider. As discussed earlier, humans have debased many species through traditional breeding methods. The wild ancestors of our current farm animals, meanwhile, are disappearing. If we are unable to save the latter, perhaps we could restore the present debased species to their original heritage by genetic engineering. [10]

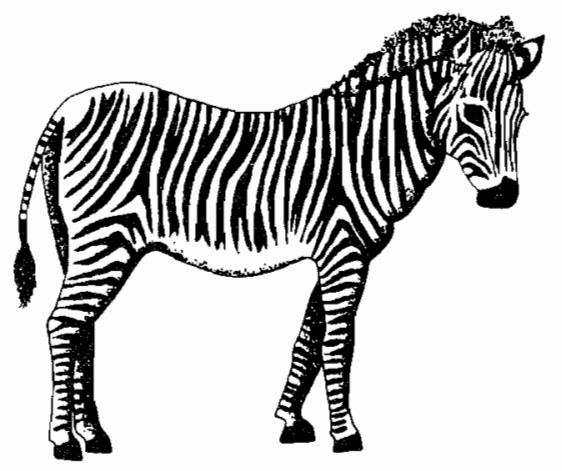

Of course, we would have to see to it that their new environments would support them, and their numbers (compared to now) would have to be greatly reduced. Suppose that this could in fact be done. Why in that case shouldn't such efforts be integrated into a sound environmental policy which would restore the species loved by Prof. Gould, as well as by many of the rest of us?

3. Now we must face another unsettling question. Could it be that all this talk of saving individuals and species "for their own good" is but another manifestation of human hubris? Yes, according to one of the most often raised abjections to genetic manipulation. We humans have always assumed that we have a godlike "manifest destiny" to interfere with nature, it is argued, but we are far fram being gods, and we have no right to redesign nature.

This argument is most often cast in religious terms. In June, 1983, an ecumenical group of clergy (joined by several scientists) petitioned congress to ban genetic engineering which could affect human inheritable traits (the germ line). The reasons they gave imply that germ line research on nonhuman animals is wrong, too. A spokesman for the group, the Rev. Avery Post, said that by doing such research "we assume the prerogative of the creator, . . and we are not good enough to do this." [11] Moreover, according to Bishop Finis Crutchfield, any efforts which, as it were, attempt to correct the Almighty smack of "pride, the deadliest of all sins."[12] Even when the objection is not put in explicitly religious terms, religious metaphors are frequently used. Gould, for example, says that "we [scientists] would not dissolve this handiwork of four billion years to satisfy the hubris of our species. We respect the integrity of nature."[13] The abjection need not be put in religious terms at all, however. It could be argued that we simply are not justified in making choices for other species (or for other members of our own species) of this radical kind. It can be argued that this pan-paternalism shows a lack of respect for others and smacks of human ego.

There is something very salutory in this objection. It underscores the importance of humility and careful consideration of the interests of others. Nevertheless, the objection goes too far. Would the critics abject to any conscious attempt to alter the germ lines of plants, nonhuman animals, and humans? In consistency, they must, even though such attempts predate the direct manipulation of genes by many centuries. There is much to deplore in much of what we have done to alter other species, and certain attempts to alter humans for "eugenic" reasons. But it would be a mistake to reject all human attempts to improve on nature. When we develop medicines to cure deadly diseases, thus allowing individuals to live and reproduce, we affect human germ lines just as surely as we would by genetic manipulation. Is this overweening pride-or is it responsible human behavior? To refuse ever to intervene in nature shows little respect for those who might be helped: it shows little respect for oneself as an intelligent moral agent. Humility is important, but it must not be confused with passivity.

The religious version of this abjection is particularly vulnerable to this reply. As Steven F. Sapontzis points out in another context, the Judeo-Christian tradition does not support a general policy of human noninterference in nature.[14] As for the "handiwork of four billion years," if one really believes it wrong to attempt to im- 
prove on chance, one would not act at all.

But is it proper to make such choices for others? When we alter embryonic animals, be they human or nonhuman (e.g., by replacing a defective gene with a properly functioning one), we choose for thern. The petition to Congress mentioned above concludes:

No individual, group or institution can legitinately claim the right or authority to make such decisions on behalf of the rest of the species."[15]

This observation can be extended to species other than our own.

Now, some individuals are unable to make the requisite choices for themselves. If we overstep our boundaries when we choose for then, we err whenever we give babies medicine or perform surgery on them. Moreover, it is certainly not the case that any of us have chosen our genes. To replace defective genes in a human or nonhuman embryo is handly to remove traits the embryo has chosen to have. of course, it would be wrong to change the genes of an individual against that individual's wishes, but who suggests such a course? I can see no objectionable paternalism here.

4. But, it will now be objected, to engage in genetic manipulation is to court ecological disaster. Rifkin rejects it as "ecological roulette: any mistake will be irretrievable."[16] Michael Fox, of the Humane Society of the United States, agrees:

We have a Pandora's box. There is no assurance that new problems of disease and suffering will not arise as the genetic makeup of animals is altered.[17]

Once again, the objection goes too far. We must indeed carefully weigh the ecological consequences of whatever we do, but it does not follow that we should do nothing. This slippery slope argument is easily applied to humans: we should do nothing to eradicate human diseases, it could be argued, because we do not know what new diseases the survivors might contract--far better not to open this Pandora's box! The reply is obvious: if new diseases arise, we should work to alleviate them as well. Responsible moral agents do not act, then stand aside passively to observe the consequences.

If the hypothetical argument of the previous paragraph seems like a caricature of the critics' objection, consider the following argument by the clergy and scientists who petitioned congress: we should not try to eradicate the defect which causes sickle-cell anemia, they urged, because the elimination of that defect "inight" increase individual susceptibility to malaria.[18] Again, the reply is obvious: ask the victims of sicklecell anemia which they would prefer, to be at greater risk of contracting malaria or to suffer from the crippling, painful, terminal disease they have. Of course, malaria is a leading cause of death in much of the world, but scientists now estimate that it--as well

as many other killer diseases--will be preventable by a safe, effective, and cheap vaccine within the next decade.[19] And what is the technique which will produce this medical breakthrough? Genetic engineering.

Many critics of genetic manipulation do not allow thenselves to be lured by the prospect of eradicating genetic disorders and other killer diseases. The following objection reveals why.

5. It is often predicted that genetic manipulation of nonhuman animals will lead to the manipulation of humans, and that no matter how benevolent our motives are at first, we will soon abuse our powers. The fear this time is not of ecological disaster it is of moral disaster. Critics fear (a) that some humans will be debased or "animalized" by genetic manipulation and (b) that manipulation will lead to a "brave new world" of artificially stunted and boosted humans.

This is the ultimate slippery slope argument against genetic manipulation of nonhumans and humans alike. Instances of this argument are sometimes rather amusing: no less a personnage than the current queen of England's former ginecologist, Sir John Peel, has warned us that the new techniques of cross-species embryo manipulation could soon lead to half-human, half-[nonhuman]animal creatures running about in laboratories. He suspects that human-chimpanzee hybrids are around the corner, if we don't ban embryo experimentation.[20] (Actually, considering the high degree of genetic similarity between humans and chimps (988), this result could 
probably be achieved by more conventional methods.) On a more serious note, Boston University theology professor $J$. Robert Nelson warns that

It may be possible to modify human life so much as to produce some theologically unacceptable notion of what human life is. We are in danger of treating human beings as animal stock rather than respecting their dignity.[21]

Treating both sentient nonhuman and human animals as 'stock' does indeed show utter disrespect for them. (Alas, there is been--abused, and not just by Nazis and their ilk. Plainly, what is needed is the very attitude which is lacking in our treatment of nonhumans: respect. This respect can result in a massive alleviation of human and nonhuman suffering, if we allow it to.

In conclusion, I have argued that genetic manipulation of sentient, nonhuman animals is not in itself ethically unjustifiable, although much current nonhuman animal research is undeniably wrong. Many important questions must still be raised, although I will not try to answer them here:

(1) We ignore the moral considerability

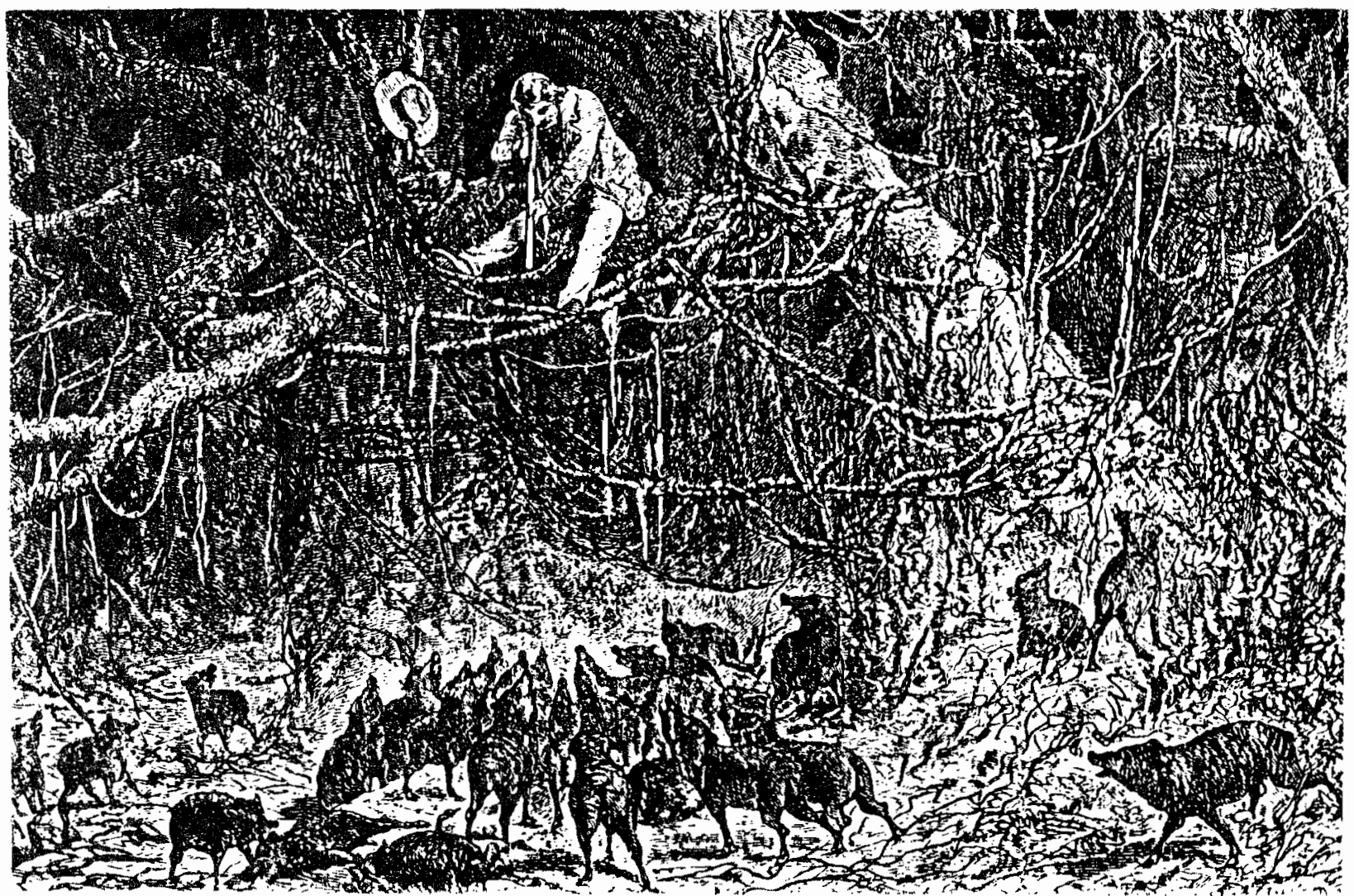

nothing very new about this, even with respect to humans. Many continue to pick their mates in the same way in which they would select a cow or a race-horse.) But do we really have any reason to fear that genetic manipulation would lead to a nightmare future in which cynical Alpha-Plus world Controllers tiurn out batches of sub- and super-humans? Surely, once again, it depends on our motivation. Abuses of this kind should certainly be banned. But why forego the stunning benefits of these new techniques because of the exceedingly slim chance that they will be abused? One may as well forego medicine and surgery because they, too, can be--and have of sentient beings if we manipulate their genes purely for our own convenience. But what about the genetic manipulation of plants? Biotechnology shows tremendous promise in this area: frost-free plants, plants that could flourish in the desert or the sea, plants that could fertilize themselves and repel pests, etc.. [22] would be a great boon for sentient beings. Obviously, we would not be doing this for the plants' "benefit." If plants are morally considerable, as many environmental ethicists argue, are we justified in conducting such research? I have argued elsewhere that even if nonsentient beings are morally considerable, it does not 
follow that they have the same moral significance as sentient beings.[23] Would this justify the research? or do plants lack moral considerability?

(2) Is there a moral difference between creating a new species and preserving an already existing one? Is the origin of a species morally relevant, or is the assumption that it is (please pardon the pun) an instance of the genetic fallacy?

(3) How far should one go in attempting to better the lot of sentient, nonhuman animals by genetic engineering? How far should we go with respect to humans?

These and other questions about the morality of genetic manipulation must be given very serious consideration. Extreme caution is called for. But, if what I have argued is correct, we must proceed--for the sake of nonhumans and humans alike.

\section{Notes}

1. "It's a Geep!," Time (February 27, 1984), p. 71 .

2. "U.S. Genetic Experiments to Alter Animals Facing Legal Challenge," The Washington Post, reprinted in The Pittsburgh Press (October 10,1984 ), p. A8.

3. "Mighty Mice," Time (Decenber 27, 1982), p. 79.

4. "U.S. Genetic Experiments," op. cit.

5. For an eloquent denunciation of farn animal domestication, see J. Baird Callicott's "Animal Liberation: A Triangular Affair." Environmental Ethics 2 (1980), p. 335.

6. One of the earliest exposes of modern factory farming remains the best: see chapter 3 of Peter Singer's Animal Liberation (New York: Avon Books, 1975).

7. Stephen Jay Gould, "On the Origin of Specious Critics," Discover (January, 1985), p. 42 (emphasis mine).

8. For some discussion of the issue, see my "Two concepts of an Environmental Ethic and Their Implications," Ethics \& Animals 4 (1983), pp. 110-27.
9. "It's a Geep!," op. cit.

10. This was suggested to me by J. Baird Callicott in private correspondence. He saw it as a way to eradicate domestic species; I see it more as a way to preserve ancestor species.

11. "Religious Leaders Oppose Genetic Engineering Tests," Associated Press Report, June 9, 1983.

12. "Scientists Must Not Play God," Time (June 20, 1983), p. 67.

13. Gould, loc. cit. (emphasis mine) Unlike the clerics, however, Gould thinks that some very limited genetic manipulation could be justified.

14. Steven F. Sapontzis, "Predation," Ethics \& Animais 5 (1984), pp. 32-3. Some Eastern religious views would have different implications.

15. "Religious Leaders," 오. cit.

16. "Scientists Must Not Play God," op. cit.

17. "U.S. Genetic Experiments," op. cit.

18. "Scientists Must Not Play God," op. cit.

19. "Renaissance for Vaccines," Disoover (September, 1984), pp. 61-3.

20. "Experiments could Produce ApeHumans, Doctors Warn," Associated Press Report (September 28, 1984).

21. "Scientists Must Not Play God," op. cit.

22. "Sowing the Seeds of Super Plants," Disoover (December, 1983). The technology for protecting plants from frost has already been developed. No applications have resulted yet because Rifkin has sued N.I.H. to halt all testing (see "U.S. Genetic Experiments," op. cit.).

23. "Two Conceptions of an Environmental Ethic," op. cit., p. 123. The same would apply to other nonsentient life forms, e.g., bacteria, which play such an essential role in current genetic manipulation. 